\title{
A APLICAÇÃO DO HOMESCHOLING NO BRASIL: UMA ANÁLISE INTERPRETATIVA À LUZ DE TRATADOS DE DIREITOS HUMANOS
}

\section{THE HOMESCHOOLING APPLICATION IN BRAZIL: AN INTERPRETATIVE ANALYSIS IN LIGHT OF RIGHT HUMANS TREATS}

\author{
Aloísio Alencar Bolwerk ${ }^{1}$ \\ Ivone dos Santos Carneiro ${ }^{2}$
}

\begin{abstract}
RESUMO
O escopo deste trabalho está objetivado em abordar a viabilidade jurídica do homeschooling no Brasil, mediante a ótica de tratados de direitos humanos ratificados pelo ordenamento jurídico pátrio, como a Convenção sobre os Direitos da Criança, a DUDH (Declaração Universal dos Direitos Humanos), e a Convenção Americana sobre Direitos Humanos (Pacto São José da Costa Rica). A pesquisa possui alicerce na metodologia indutiva, utilizando como subsídios a análise da estrutura didática e metodológica, dos impactos positivos e negativos da educação domiciliar, bem como da forma que o ordenamento jurídico brasileiro acompanha o aumento do número de adeptos à prática do ensino desescolarizado no país.
\end{abstract}

Palavras-chaves: Convenção sobre os Direitos da Criança. Declaração Universal dos Direitos Humanos. Educação Domiciliar. Homeschooling. Pacto São José da Costa Rica.

\section{ABSTRACT:}

The scope of this work is aimed at addressing the legal viability of homeschooling in Brazil, through the perspective of human rights treaties ratified by the national legal system, such as the Convention of the Rights of the Child, the UDHR (Universal Declaration of Human Rights), and the American Convention on Human Rights (Pact of San José). The research is based on the inductive methodology, using as subsidies the analysis of the didactic and methodological structure, the positive and negative impacts of home education, as well as the way that the Brazilian legal system follows the increase in the number of adherents to the practice of unschooled teaching in Brazil.

1 Doutor em Direito Privado pela Pontifícia Universidade Católica de Minas Gerais. Professor Adjunto das disciplinas de Hermenêutica jurídica e Direito Constitucional da Universidade Federal do Tocantins - UFT e de Teoria Geral do Direito do CEULP/ULBRA. Advogado. Email: bolwerk@uft.edu.br. ORCID https://orcid.org/0000-0003-4229-4337

2 Bacharel em Direito da Universidade Federal do Tocantins - UFT; e-mail: ivonecarneiro.19@mail.uft.edu.br. ORCID https://orcid.org/0000-0002-7083-505X 
Key-words: Convention of the Rights of the Child. Universal Declaration of Human Rights. Home education. Homeschooling. San Jose Pact of Costa Rica.

\section{INTRODUÇÃO}

Busca-se neste trabalho, abordar a viabilidade jurídica do homeschooling no Brasil, mediante a ótica de tratados de direitos humanos. A pesquisa norteia-se no levantamento de reflexões, a fim de compreender a abordagem dada por tratados de direitos humanos ao homeschooling. Ato contínuo, é realizada uma análise, embasando como justificativa e pertinência temática, a necessidade de identificar 0 acompanhamento dado pelo ordenamento jurídico brasileiro à aplicação da educação domiciliar. Mister se faz, empreender a busca de subsídios para esclarecer sobre a estrutura didática e metodológica, bem como descortinar os impactos positivos e negativos da modalidade de ensino em evidência.

O estudo possui alicerce em uma metodologia indutiva. $O$ processo investigativo inicia-se por meio de uma observação que fornece base segura sobre a qual o conhecimento científico pode ser construído, sendo obtido a partir da observação por indução. O método exige um exercício de concretização do Direito aplicável à realidade social, por meio de uma observação à luz do padrão constitucional e através de um procedimento argumentativo e racionalmente controlável. É necessária uma interpretação de caráter prático, em que a discussão do problema revela-se com maior primazia sobre a discussão da norma em si.

A partir do momento em que o debate é centrado no óbice, critérios e princípios são levantados para a resolução apropriada, advindo a coleta, classificação e análise de fontes como materiais bibliográficos, tabelas, estatísticas, análises de casos e matérias jornalísticas, para a compreensão e deslinde do tema. Dessa forma, também são utilizados métodos históricos, comparativos e empíricos no desenrolar da pesquisa.

Nesse sentido, a pergunta levantada é, ante a relação entre os Tratados de Direitos Humanos em que o Brasil é signatário, e a educação, qual a abordagem da ordem jurídica brasileira quanto a aplicação do homeschooling no país? Com os resultados encontrados, busca-se pela elaboração de referenciais bibliográficos sobre o tema. A investigação proporciona o aclaramento quanto ao que dispõem tratados de 
direitos humanos sobre a educação, e até que ponto as diretrizes podem influenciar no sistema normativo jurídico do país e na realidade social das famílias brasileiras que optam pela educação domiciliar.

\section{CONSIDERAÇÕES ELEMENTARES}

De acordo com Andrade (2014, p. 19), o homeschooling, termo oriundo do idioma inglês, é a palavra utilizada, amiúde, nos EUA (Estados Unidos da América) e adotada internacionalmente para indicar a prática em que os pais assumem a responsabilidade dos processos educacionais dos filhos, promovendo a educação em casa, ao invés da escolarização.

Andrade (2014, p. 19), pontua que o termo é comumente traduzindo para o Português por Educação Domiciliar e que a expressão escola no gerúndio (schooling), sem detença, propõe o modelo de educação constante. Isto é, as abordagens de ensino adotadas pelos pais oferecem um aprendizado contínuo, inserindo no cotidiano da família, atividades costumeiras ou não, que podem ser voltadas para o aprendizado, como refeições, passeios, viagens, encontros de famílias, dentre outros.

De acordo com a Aned (2019), a educação domiciliar está presente nos cinco continentes, estando admitida ou regulamentada em mais de 60 países, sendo praticado em países como EUA, Canadá, México, Chile, Equador, Colômbia, Portugal, Áustria, Bélgica, França, Itália, Suíça, Bulgária, Dinamarca, Finlândia, Rússia, Reino Unido, Israel, África do Sul, Japão, Filipinas, Cingapura, Canadá, Austrália e Nova Zelândia.

Segundo Ray (2015, p. 3), professor universitário e presidente do NIERI (National Home Education Research Institute), os EUA foi o primeiro país onde a educação domiciliar alcançou números expressivos de adeptos ainda na década de 1970. Em 2017 os EUA contavam com a efetiva legalização da prática nos 50 estados, aferindo em 2,5 milhões o número de crianças homeschoolers.

Para Moreira (2017, p. 59) , "a educação domiciliar é com nitidez uma espécie de educação não formal, alternativa ao modelo escolarizado de educação". Nessa perspectiva, é importante ressaltar que o objetivo da educação, conforme Aristóteles 
(1991, p. 129, 135-136) é produzir a criação da mente sadia em um corpo sadio, desenvolvendo o homem para o usufruto da verdade, da bondade e da beleza. Outrossim, segundo Kumar (2008, p. 57) a educação compreende o rematado desenvolvimento da individualidade da criança para que ela se torne apta a oferecer 0 melhor de sua capacidade material e espiritual para a vida humana.

Nessa busca pelo desenvolvimento da individualidade da criança, através do homeschooling, foi que surgiu no Brasil em 2010, como entidade não governamental, a ANED (Associação Nacional de Educação Domiciliar).

De acordo com a Aned (2019), a educação domiciliar no Brasil, é um fenômeno consolidado, que surgiu, no país, no início da década de 90, apresentando um crescimento de mais de $2000 \%$ nos últimos 8 anos, e estando hoje, presente nas vinte e sete unidades da federação. Ainda segundo a Aned (2019), o número de famílias educadoras no país saltou de cerca de 360 no ano de 2011, para 7500 famílias em 2018, com cerca de 15000 estudantes, com idade entre quatro e dezessete anos.

Em setembro de 2018 houve, na Suprema Corte do país, o julgamento do Recurso Extraordinário 888.815/RS. O caso oriundo da cidade de Canela/RS, discutiu sobre a possibilidade jurídica de uma família educar a filha menor, sem a necessidade da frequência escolar. Os ministros ressaltaram quanto a necessidade da socialização que a escola pode oferecer e, arrazoando a inexistência de previsão legal para o ensino na modalidade domiciliar, por 9 votos a 1, decidiram pelo desprovimento do pedido feito pela família.

De acordo com a Aned (2019), a escola não é o principal meio de socialização, visto que a socialização está ligada aos relacionamentos entre pessoas de diferentes faixas etárias, o que não ocorre nas salas de aulas, aonde as turmas são separadas exatamente para que a convivência seja com crianças da mesma idade. Baseada em dispositivos de Tratados de Direitos Humanos, a Aned (2019) compreende que a prioridade nas escolhas relacionadas à educação dos filhos menores é dos pais e não do Estado, justificando o respeito à liberdade de escolha entre praticar homeschooling e/ou aderir à educação escolarizada.

Observa-se, dessa forma, a existência de uma problemática. Subsistem dois entendimentos antagônicos sobre uma prática cujo número de adeptos cresce de forma 
significativa no país. Ademais, apesar da negativa do STF (Supremo Tribunal Federal), famílias homeschoolers continuam aplicando a educação domiciliar, acreditando na legalidade e legitimidade do ensino desescolarizado.

Um dos pontos levantados na peça inaugural do recurso acima mencionado, foi a alegação de que impedir a liberdade de escolha entre a escolarização e a educação domiciliar no Brasil, seria como vulnerabilizar preceitos da DUDH, além de desconsiderar a supralegalidade dos tratados e convenções de direitos humanos internalizados ao ordenamento jurídico pátrio. E é a partir desse aspecto que se inicia o deslinde do primeiro capítulo deste trabalho.

\section{DOS TRATADOS DE DIREITOS HUMANOS}

Entrando nesse diapasão dos tratados, importa ressaltar que a pesquisa busca compreender quanto a contribuição de tratados de direitos humanos ratificados pelo Brasil, no que se refere à educação domiciliar. São eles, Convenção sobre os Direitos da Criança, a DUDH e o Pacto São José da Costa Rica.

A título de amparo na percepção do conteúdo que este trabalho se propôs evidenciar, se faz necessário discorrer sumariamente a respeito do que a doutrina chama de "bloco de constitucionalidade". Ademais, é mister, outrossim, trazer a baila o que pontua a doutrina quanto ao status constitucional de alguns tratados, adentrando imperiosa e brevemente ao controle de convencionalidade no Direito Brasileiro.

Segundo Boareto (2014, p. 10), o termo "bloco de constitucionalidade", que teve origem na França, consiste no composto normativo que atua como indicador na realização do controle de constitucionalidade, compreendendo no caso, normas expressas ou não no texto constitucional. Quando se trata de "bloco de constitucionalidade", a referência é no tocante a um conceito que permite ao intérprete, estender a ótica de normas constitucionais para além daquelas conjecturadas expressamente na redação constitucional.

O conceito de "bloco de constitucionalidade" também aparece nas discussões jurisprudenciais. Foi tratado pelo Ministro Celso de Mello no julgamento da ADI 595-ES (Inf. 258/STF). Na apreciação, frisou, o julgador, quanto aos elementos essenciais do 
controle de constitucionalidade, dentre eles o elemento conceitual ("bloco de constitucionalidade"). De acordo com o Ministro Celso de Mello (Inf. 258/STF), o elemento conceitual "consiste na determinação da própria ideia de Constituição e na definição das premissas jurídicas, políticas e ideológicas que lhe dão consistência".

Esclareceu ainda em seu discurso, que é cabível uma perspectiva ampliativa, suscitando que no controle de constitucionalidade, podem ser considerados não apenas o conteúdo expresso na norma constitucional, mas também os valores de roupagem supra positivas, os princípios com cernes no direito natural e o próprio espírito que propõe sentido à Lei Fundamental do Estado.

Mazzuoli (2018, p. 232, 233), ressalta que, por influência dos debates doutrinários e jurisprudenciais, e com o objetivo de encerrar polêmicas até então existentes, no tocante à hierarquia dos tratados de direitos humanos mediante o controle de convencionalidade, foi inserido o $\S 3^{\circ}$ ao art. $5^{\circ}$ da Constituição, por meio da Emenda Constitucional n. .45 , de 8 de dezembro de 2004, para determinar que todos os tratados e convenções internacionais que versem sobre direitos humanos, desde que aprovados em cada Casa do Congresso Nacional, em dois turnos, por três quintos dos votos, serão congêneres às emendas constitucionais.

Nesse sentido, constata-se, que os tratados de direitos humanos aprovados em conformidade com $\circ \circ \S 3^{\circ}$ ao art. $5^{\circ}$ da Carta Magna, alcançarão status constitucional tendo, portanto, paridade com o texto da Lei Maior. MAZZUOLI (2018, p. 241), outrossim, pontua quanto da supralegalidade, assunto de extrema relevância e seguramente indispensável para uma compreensão perspicaz do tema a que se propõe estudar nesta pesquisa. Mazzuoli (2018, p. 241), elucida que dentro do controle de convencionalidade, procedimento que busca, de forma concentrada ou difusa, verificar a harmonia vertical dos tratados e convenções de direitos humanos com as normas internas, há o controle de supralegalidade.

A supralegalidade, conforme assinala Mazzuoli (2018, p. 284), é uma das vertentes do processo de compatibilização dos tratados de direitos humanos com o ordenamento jurídico pátrio, que conjectura quais tratados de direitos humanos ajustam-se em posição hierarquicamente superior às normas infraconstitucionais e inferior ao texto constitucional. 
Segundo preceitua Varella (2011, p. 93 - 95), os tratados de direitos humanos introduzidos ao ordenamento jurídico pátrio antes da Emenda Constitucional 45/2004, embora não possuam aspecto constitucional capazes de apresentarem paridade ao texto da Carta Magna, em obediência ao $\S 2^{\circ}$ do art. $5^{\circ}$ da Constituição, posicionam-se severamente acima das normas infraconstitucionais, assumindo assim, a supralegalidade e integrando, juntamente do texto constitucional, o "bloco de constitucionalidade".

Nessa ambiência, o Supremo Tribunal Federal, solidificou o entendimento quanto a supralegalidade dos tratados e convenções de direitos humanos, ao julgar o RE 349703/RS. Compactuando, portanto, com a expansão do "bloco de constitucionalidade". Colacionado abaixo vultoso julgamento da Suprema Corte.

PRISÃO CIVIL DO DEPOSITÁRIO INFIEL EM FACE DOS TRATADOS INTERNACIONAIS DE DIREITOS HUMANOS. INTERPRETAÇÃO DA PARTE FINAL DO INCISO LXVII DO ART. 50 DA CONSTITUIÇÃO BRASILEIRA DE 1988. POSIÇÃO HIERÁRQUICO-NORMATIVA DOS TRATADOS INTERNACIONAIS DE DIREITOS HUMANOS NO ORDENAMENTO JURÍDICO BRASILEIRO. Desde a adesão do Brasil, sem qualquer reserva, ao Pacto Internacional dos Direitos Civis e Políticos (art. 11) e à Convenção Americana sobre Direitos Humanos Pacto de San José da Costa Rica (art. 7º, 7), ambos no ano de 1992, não há mais base legal para prisão civil do depositário infiel, pois o caráter especial desses diplomas internacionais sobre direitos humanos lhes reserva lugar específico no ordenamento jurídico, estando abaixo da Constituição, porém acima da legislação interna. O status normativo supralegal dos tratados internacionais de direitos humanos subscritos pelo Brasil torna inaplicável a legislação infraconstitucional com ele conflitante, seja ela anterior ou posterior ao ato de adesão. Assim ocorreu com o art. 1.287 do Código Civil de 1916 e com o Decreto-Lei n ${ }^{\circ}$ 911/69, assim como em relação ao art. 652 do Novo Código Civil (Lei $n^{\circ}$ 10.406/2002). (RE 349703/RS, julgado em 03/12/2008, grigo nosso).

Feitas as ponderações relevantes quanto a supralegalidade no direito constitucional pátrio, atinge-se as discussões inerentes à abordagem feita por tratados de direitos humanos ratificados pela ordem jurídica brasileira no tocante à educação domiciliar. Tratados os quais integram o "bloco de constitucionalidade" e estão posicionados hierarquicamente acima das normas infraconstitucionais, conforme 
esclarecimento exposto nos parágrafos acima. A partir de agora serão abordadas as contribuições da Convenção sobre os Direitos da Criança, no que se refere à possibilidade jurídica da prática do homeschooling no Brasil. E como subsídio, expõe-se também pressupostos conjecturados na DUDH e no Pacto São José da Costa Rica.

A Convenção sobre os Direitos da Criança, internalizada ao direito brasileiro por meio do Decreto 99.710/1990, possuindo roupagem supralegal, em seu artigo 5으, prevê que o Estado deve respeitar as responsabilidades, os direitos e os deveres dos pais e dos membros da família, de proporcionar à criança, instrução e orientação apropriada e de acordo com a evolução da capacidade da criança.

Esse dispositivo, de acordo com Moreira (2017, p. 109), garante aos pais o respeito ao seu direito de, mediante o poder familiar, conduzir a instrução dos filhos menores, cabendo, dessa forma, a prática do homeschooling, já que através da educação domiciliar, os pais assumem a responsabilidade quanto à instrução e educação das crianças e adolescentes conforme o desenvolvimento individual das capacidades de cada um dos filhos.

A DUDH, tratado sui generis, adotada e proclamada pela resolução 217-A da Assembleia Geral das Nações Unidas em 10 de dezembro de 1948, é uma proclamação da vontade dos países soberanos, e sua natureza é moral, cuja vinculação gera compromisso ético-comportamental, no sentido de standatizar condutas internacionais.

A partir da DUDH, os Estados-Soberanos passaram a aderir ao seu conteúdo nas Cartas Constitucionais, a exemplo a Constituição da república Federativa do Brasil de 1988. É evidente a influência da DUDH para a construção normativa dos direitos fundamentais previstos no vigente texto constitucional, como os direitos à educação, à liberdade, à vida, à segurança, dentre outros, que estão difundidos por toda a Carta Magna e são facilmente identificados no artigo $5^{\circ}$ desta, dispositivo notadamente erigido ao status de cláusula pétrea, cuja alteração encontra enérgicas reservas na Constituição.

No que se refere à sua vinculação ao ordenamento jurídico brasileiro, se deu com diversos tratados internacionais de direitos humanos promulgados a partir da década de 1960, dentre os quais destacam-se o Pacto São José da Costa Rica, 
promulgado pela OEA (Organização dos Estados Americanos) em 1969 e ratificada pelo Brasil em 1992, e a Convenção sobre os Direitos da Criança, promulgada pela ONU (Organização das Nações Unidas) em 1990 e ratificada pelo Brasil no mesmo ano.

Nessa ambiência, inicia-se a abordagem quanto a DUDH no que se refere a prática da educação domiciliar. A DUDH preconiza em seu artigo 16.3 que "a família é o núcleo natural e fundamental do corpo social e deve receber proteção da sociedade e do Estado". Observa-se que esse dispositivo em consonância com o artigo 18, que conjectura que "todo ser humano tem direito a liberdade de pensamento e de manifestação de crença pelo ensino", demonstra significativo fundamento jurídico para as famílias homeschoolers no sentido de que o Estado deve garantir o direito dos pais educarem seus filhos em casa ou na escola, sem a obrigatoriedade do ensino escolarizado, desde que os pais se responsabilizem pela instrução primária dos menores.

Identifica-se também que 0 artigo 26, nos pontos 1,2 e 3 , ressalta respectivamente que, nenhum ser humano pode ficar sem instrução, que o objetivo de tal instrução é o pleno desenvolvimento da personalidade humana e do respeito aos direitos humanos, e que os pais possuem a prioridade na escolha do gênero de instrução que será ministrada a seus filhos. Coaduna-se por meio desse dispositivo, que todo indivíduo deve receber algum tipo de conhecimento com a finalidade de desenvolver seu máximo potencial humano de maneira produtiva no mercado de trabalho e na sociedade, priorizando os pais em detrimento do Estado na escolha do tipo de educação que será oferecida.

Observa-se, que nesse ponto, a grande preocupação é garantir que as crianças e adolescentes sejam preparadas para a vida adulta e autônoma, independente do local aonde a instrução será ofertada. Cabendo dessa forma, uma visão interpretativa, possibilitando assim, tanto a frequência escolar, quanto a educação domiciliar.

Moreira (2017, p. 164), expõe que a DUDH dá enfoque em conferir ao poder familiar, o papel central na educação dos filhos, resguardando a importância do poder e da liberdade familiar, garantindo assim a proteção desses direitos. $O$ autor colaciona 0 
artigo 26.3 da Declaração, que dá prioridade aos pais quanto a escolha do gênero de educação a ser dada aos filhos.

Segundo Moreira (2017, p.164), a linguagem usada na DUDH para resguardar aos pais o direito fundamental de escolher o tipo de educação a ser dada aos filhos, reflete a experiência trágica de violações maciças, dos direitos humanos inalienáveis, sob o domínio nazista. Onde a educação escolarizada era um dos meios para alienação ideológica do regime de Hitler, e os pais que se negavam a oferecer seus filhos à educação escolarizada eram perseguidos pelo Estado.

O art. 26.3 é um dos artigos da DUDH moldados com mais clareza pela experiência de guerra. Sob o governo nazista o direito em destaque no presente artigo foi violado. Os pais que tentaram manter seus filhos fora da juventude Hitlerista e de outros instrumentos de doutrinação ideológica nazista, incluindo-se o sistema escolar público nazista, foram acusados de "abusar da autoridade parental" e perseguidos. Essa experiência de abuso do poder do Estado para doutrinação ideológica e lavagem cerebral na educação foi, de fato, a razão histórica real para introduzir a linguagem em questão na DUDH. Trata-se de um fato histórico claro e bem documentado. (MOREIRA, 2017, p. 164)

Além das previsões indicadas pela DUDH, a liberdade, a prioridade e a responsabilidade familiar no tocante à educação dos filhos menores para a prática do homeschooling, encontra amparo no Pacto São José da Costa Rica, tratado ratificado pelo Brasil através do decreto 678/92, que, compondo o "bloco de constitucionalidade" e sobreposto a eventual legislação infraconstitucional, garante à família o direito de formação moral dos filhos.

Observou-se se que, conforme art. 11, tópicos 2 e 3 do referido tratado, nenhuma pessoa pode sofrer interferências arbitrárias ou abusivas, devendo o Estado garantir a proteção da lei contra ingerências ou ofensas à vida privada ou à família. No tópico 4 do artigo seguinte está conjecturado que "os pais, e quando for o caso os tutores, tem direito que seus filhos ou pupilos recebam a educação religiosa e moral que esteja acorde com suas próprias convicções". No art. 17, tópico 1, o Pacto São José da Costa Rica, resguarda ainda que "a família é o elemento natural e fundamental da sociedade e deve ser protegida pela sociedade e pelo Estado" (ONU, 1992). 
Pontua Schelb (2015, p. 10), que os dispositivos acima mencionados estabelecem que a formação moral da criança incumbe à sua família, o que resguarda sublimemente o direito dos pais de escolher se querem educar seus filhos através da escolarização ou se optam pela prática do homeschooling, visto que o art. 26.3 da DUDH, aponta que a primazia na escolha do gênero de instrução que será ministrada aos menores, é dos pais e não do Estado.

Analisando os tratados estudados, verifica-se que os referidos documentos compõem o "bloco de constitucionalidade" e possuem status de norma supralegal, o que significa dizer que estão posicionados acima das normas infraconstitucionais e, embora abaixo do texto constitucional, integram o conteúdo material para o controle de convencionalidade.

Ademais, ao examinar o conceito de educação e investigar quanto a abordagem feita pelos tratados explorados, observa-se que tais documentos cooperam no sentido de amparar o ensino domiciliar no país, visto que não apresentam dispositivos para vedar o ensino desescolarizado. Pelo contrário, favorecem a defesa da prática no Brasil, já que ampliam a interpretação quanto à possibilidade jurídica do homeschooling.

\section{DO ORDENAMENTO JURÍDICO BRASILEIRO}

Além dos tratados de direitos humanos, que internalizados ao ordenamento jurídico pátrio possuem roupagem supralegal e compõe o "bloco de constitucionalidade", dentre as normas internas do Direito brasileiro, que possuem relação com a educação domiciliar, pode-se citar a Constituição, a LDB (Lei de Diretrizes e Bases da educação), o ECA (Estatuto da Criança e do Adolescente), e o Código Penal. De todos estes, apenas a Constituição prevalece perante a Convenção sobre os Direitos da Criança e o Pacto São José da Costa Rica.

A Carta Magna, conjectura, em seu artigo 227, que a educação é dever da família, da sociedade e do Estado. A LDB, Lei oㅜ 9.394 de 1996, em seu artigo 6ㅜㅡ, juntamente com o artigo 55 do ECA, Lei o 8.069 de 1990, prevê a obrigatoriedade da matrícula escolar de crianças a partir dos quatro anos de idade. O Código Penal 
considera que os pais ou responsáveis que deixam, sem justa causa, de prover à instrução primária ao filho em idade escolar, praticam o crime de abandono intelectual.

A Constituição da República Federativa do Brasil resguarda o direito do menor de receber educação da sua família, da sociedade e do Estado. E, na busca pelo respeito e proteção à criança e ao adolescente, buscou o legislador, positivar em outros dispositivos constitucionais e infraconstitucionais, a determinação da matrícula do menor em instituição regular de ensino, bem como penalizar os responsáveis que se neguem a promover tal matrícula, sem deixar expressamente, margem para outra possibilidade de educação que não fosse a escolarizada.

Essas normas foram criadas entre os anos de 1940 e 1996, período em que o homeschooling ainda não era uma realidade no país. Conforme exposto em tópico específico deste trabalho, a educação domiciliar surgiu no Brasil, timidamente, em meados da década de 1990, evoluindo ao longo dos anos, e tornando-se uma realidade difundida a partir no início dos anos 2000.

Outro ponto que precisa ser observado, é que a realidade social do Brasil na década de 1990, era de um cenário de desrespeito à infância e à juventude, em que os índices de trabalho infantil com crianças e adolescentes entre 10 e 15 anos, atingia um percentual de 23,63\%, no ano 1992 (IBGE, 2009). Daí se explica a preocupação do legislador em obrigar a família em promover a matrícula escolar, e considerando que a educação domiciliar ainda não era uma modalidade de ensino expressiva, a única opção vislumbrada pelo legislador para combater o trabalho infantil foi o ensino escolarizado.

O Código Penal Brasileiro, Decreto-Lei № 2.848 de 1940, tipifica em seu artigo 246, o crime de abandono intelectual, o qual prevê pena de detenção ou multa para os responsáveis que deixam, sem justa causa, de prover à instrução primária de filho menor em idade escolar. O dispositivo, segundo a Aned (2019), é muito utilizado por Conselheiros Tutelares para desaprovar as famílias que praticam a educação domiciliar sem a matrícula e frequência escolar.

Nucci (2014, p. 1001) ressalta que deixar de prover quer dizer ausência de providência da parte dos pais. Quanto ao termo "sem justa causa", Nucci (2014, p. 1001) pontua que se trata de crime omissivo e significa algo ilícito ou não amparado por 
lei. Logo, é um elemento de antijuridicidade colocado dentro do tipo penal. Portanto, considerando que existem tratados e convenções supralegais que amparam a prática, e que não há norma jurídica que criminalize a educação domiciliar, esta não poderia ser enquadrada na interpretação do tipo penal do art. 246 do Código Penal Brasileiro.

Buscou o legislador, por meio do art. 246 do Código Penal, evitar que menores com idade entre 4 e 17 anos, viessem a ficar sem instrução educacional. E, em uma família onde se pratica o homeschooling vê-se que há uma elevada preocupação com a educação dos filhos, a ponto de adequar toda a rotina da família para oferecer uma educação personalizada, conforme conjectura art. $6^{\circ}$ do ECA, que ressalta a atenção às exigências dos deveres e direitos individuais, e a condição peculiar do menor como pessoa em desenvolvimento.

No que se refere ao cenário jurisprudencial, em 12 de setembro de 2018, por meio do julgamento do RE 888.815/RS, a Suprema Corte apadrinhou a necessidade da socialização oferecida pela escola e, justificando a ausência de expresso texto normativo, entendeu pela impossibilidade jurídica do homeschooling no país. Deixando a cargo do legislativo, se assim entender, a idealização de uma lei para regulamentar ou amparar, de forma expressa, o ensino domiciliar no país.

Dentre as propostas legislativas, observa-se algumas com expressivo avanço. O PL 3179/12 que prever alteração da LDB e do ECA, no sentido de dispor sobre a possibilidade de oferta domiciliar na educação básica, conta com parecer favorável e aguarda desde o dia 22 de outubro de 2019, a criação de comissão especial temporária, para apreciação conclusiva. O PL possui três outros pedidos que foram a ele apensados, por tratarem do mesmo tema e propósito, dentre tais, o PL 2401/2019, oriundo do Poder Executivo. Há ainda em apenso ao PL 3179/2012, a proposta legislativa 3159/2019 que foi apensada àquele mas busca intento contrário, o qual é impedir que a educação domiciliar substitua a frequência escolar.

No Senado Federal, tramitam o PLS 490/2017 e o PLS 28/2018. O primeiro sugere modificações na LDB e no ECA para conjecturar a modalidade da educação domiciliar no âmbito da educação básica, e o segundo, prever alteração do Código Penal para que seja definido expressamente que a educação domiciliar não caracteriza o crime de abandono intelectual. 
Conforme pautado nas considerações iniciais, vive-se hoje uma realidade onde o número de famílias homeschoolers cresce intensamente, e no cenário mundial, a educação domiciliar se mostra como um fenômeno presente nos cinco continentes e com reconhecimento em mais de sessenta países. Nesse diapasão, ignorar as diferenças sociológicas e temporais da realidade social brasileira desde a época de criação do ECA, da LDB e do Código Penal, até os dias atuais, é como negligenciar a existência de novos formatos pedagógicos, bem como fechar os olhos aos avanços educacionais dispostos.

\section{ESTRUTURA DIDÁTICA E METODOLÓGICA DO HOMESCHOOLING NO BRASIL}

Inicialmente, é importante destacar três conceitos essenciais, o que é educação, o que é educação escolarizada e o que é educação domiciliar. Educação, conforme preceitua Durkheim (1978, p. 41), é a "ação exercida pelas gerações adultas sobre as que ainda não amadureceram pela vida social; tem por objeto suscitar e desenvolver na criança um certo número de estados físicos, intelectuais e morais [...]".

Educação escolarizada, conforme expõe Moreira (2017, p. 34), diz respeito a um conjunto de "processos de caráter educacional controlados por uma instituição específica, a escola", denominada também pelo autor, como "educação formal" visto que está submetida aos moldes determinados pelo Estado. A educação domiciliar, objeto medular deste trabalho, de acordo com Moreira (2017, p. 59), "é uma espécie de educação não formal, alternativa ao modelo escolarizado de educação".

Para Moreira (2017, p. 62, 63), a educação domiciliar é uma proposta de ensino que não obedece um método ímpar. O objetivo central, é respeitar a soberania educacional da família, permitindo a liberdade para que os pais possam definir como será realizada a educação dos filhos menores. Dessa forma, a família pode oferecer os conteúdos de maneira personalizada, de acordo com as individualidades e o desenvolvimento de cada criança.

Por esse motivo, conforme Moreira (2017, p. 62, 63), diferentes abordagens podem ser adotadas, dependendo da realidade de cada família e das diferenças de 
cada criança. Dentre os modelos de educação domiciliar, há alguns que se destacam e merecem ser aqui exibidos:

a) Inteligências múltiplas: Apresenta um processo educacional focado no tipo específico de inteligência da criança. Sustenta-se na tese de que todo ser humano é inteligente a seu próprio modo e que por essa razão o aprendizado será muito mais eficiente se o educando for encorajado a usar seus pontos fortes ao invés de seus pontos fracos. Dentre os tipos de inteligência compreendidas pela teoria, pode-se citar linguística, corporal, musical, espacial, interpessoal, intrapessoal e lógico-matemática.

b) Montessori: Possui ênfase na independência e no respeito ao desenvolvimento físico psicológico e social da criança. Apresenta seis pilares, a autoeducação, a educação como ciência, a educação cósmica, o ambiente preparado, o adulto preparado e a criança equilibrada;

c) Eclética/Flexível: Adaptada às necessidades e mudanças da criança e da família. Não utilizando um método único, é a abordagem mais utilizada pelas famílias educadoras;

d) Charlotte Mason: tem a educação a partir de três componentes, a atmosfera, a disciplina e a vida, o primeiro tem a ver com o ambiente em que a criança se desenvolve, isto é, as ideias que conduzem a vida dos pais são responsáveis por um terço da educação dos filhos, a segunda se refere ao cultivo dos bons hábitos formadores de caráter, é onde situa outro terço da educação, e o terceiro diz-se que devem ser dados a criança exemplos de ideias e pensamentos vivos, jamais de fatos vazios.

e) Clássica: Na educação clássica, o aprendizado acontece em três fases, denominada Trivium, primeiro a fase da gramática, depois da lógica e por fim da retórica. São utilizadas as grandes obras literárias ocidentais e tem duas grandes vertentes: a educação clássica cristã e a educação clássica secular. O objetivo fundamental não é ensinar conteúdos, é ensinar a aprender.

f) Waldorf: Esse modelo de ensino procura integrar o desenvolvimento físico, espiritual, intelectual e artístico dos alunos. O objetivo é criar indivíduos livres, socialmente competentes e responsáveis em sentido moral. 
Observa-se que o processo educacional para o aprendizado por meio do homeschooling pode apresentar-se com diferentes abordagens, não possuindo uma estrutura didático-metodólogica específica, já que cada família é responsável por decidir qual metodologia utilizará no processo educacional, considerando o desenvolvimento da criança, o seu tipo de inteligência e as inúmeras individualidades de cada educando, bem como, de cada núcleo familiar, para que o menor possa, como proposto por Kumar (2008, p. 57), promover o desenvolvimento, a maturação e o florescimento do seu máximo potencial individual para a vida humana.

Quanto a certificação de ensino fundamental e médio junto ao MEC (Ministério da Educação), de acordo com a Aned (2019), o meio utilizado pelas famílias para conseguir certificação educacional no Brasil, é submeter o filho, após a maioridade, à prova do ENCCEJA (Exame Nacional para Certificação de Competências de Jovens e Adultos).

O ENCCEJA é uma avaliação do INEP (Instituto Nacional de Ensino e Pesquisas Educacionais Anísio Teixeira) criada em 2002 por meio da Portaria № 2.270, com o intento de medir o conhecimento das pessoas que retornaram aos estudos porque não alcançaram a conclusão do ensino fundamental ou médio na idade adequada. No ano de 2017, o MEC passou a admitir o ENCCEJA para a certificação do ensino médio, independente da frequência escolar ou de atrasos na idade educacional, função que foi assumida pelo ENEM (Exame Nacional do Ensino Médio) entre os anos de 2009 e 2016. Segundo dados da ANED (2019), o percentual de aprovação dos homeschoolers brasileiros, mediante a avaliação do ENCCEJA, é de 100\%.

De acordo com dados divulgados pela Aned (2019), no ano de 2016 cerca de um terço $(32 \%)$ das famílias homeschoolers, buscavam na educação domiciliar, uma educação personalizada para os filhos, a fim de explorar seus potenciais e talentos. Em 2017, em levantamento com 285 famílias, a Aned (2019) identificou que 34\% possui ensino superior completo, e em $74 \%$, um dos pais já frequentou ou frequenta uma Universidade. Em 2018, em pesquisa com 1209 pais simpatizantes com a educação domiciliar, mas que ainda mantém os filhos na escola, a Aned (2019) expôs que 68\% afirmam ter interesse em praticar homeschooling, e os demais aguardam a regulamentação para aderir. 
Nesse diapasão emerge uma interessante reflexão, que pode ser tratada em um próximo trabalho. Se o Estado passa a conceder certificados de ensino fundamental e médio, sem a exigência de matrícula escolar para pessoas que possivelmente não praticam nenhum tipo de ensino organizado como o homeschooling. Seria, talvez, incoerente, obrigar a matrícula escolar nos casos das famílias que se mostram aptas a oferecer educação domiciliar e ainda comprovam a efetividade da prática através de exames nacionais.

Para concluir os objetivos desta pesquisa, investigou-se ainda quanto aos impactos positivos e negativos do homeschooling, desenlace que explanado no próximo tópico deste trabalho.

\section{IMPACTOS POSITIVOS E NEGATIVOS}

Em 2003, quando os EUA contavam com a sua primeira geração de adultos que foram educados mediante o ensino domiciliar, o Dr Brian D. Ray conduziu um detalhado estudo com cerca de 7.300 adultos com idade média entre 16 e 29 anos que foram alunos homeschoolers, onde 5000 deles estudaram em casa por no mínimo sete anos, a fim de identificar os impactos da educação desescolarizadas na vida adulta dessas pessoas. REY (2003), cruzou os dados de seu levantamento sobre alunos homeschoolers com os disponibilizados pelo Governo norte-americano, referente aos adultos que foram educados na rede regular de ensino e que à época do censo também contavam com idade entre 16 e 29 anos.

O estudo comprovou que $74 \%$ dos adultos que foram educados em casa, já haviam ingressado na faculdade e concluído algum nível de graduação, enquanto apenas $46 \%$ dos educados em escolas convencionais, possuíam tal diplomação. Demonstrando que adultos homeschoolers estão mais propícios a dar continuidade na rotina acadêmica. A pesquisa concluiu também que, no tocante ao assunto engajamento social, cerca de $71 \%$ dos adultos homeschoolers praticavam alguma atividade comunitária como participação em associações, comunidades, grupos religiosos, etc, enquanto apenas $37 \%$ dos adultos educados no modelo escolarizado tinham esse envolvimento social. 
No que se refere ao comprometimento civil, o estudo deixou demonstrado que os educados em casa estão mais dispostos ao envolvimento político. Somente $4.2 \%$ dos homeschoolers consideraram política e governo um assunto muito complicado de entender, comparado com $35 \%$ dos seus pares. Os homeschoolers que votaram nos últimos 5 anos representavam $76 \%$ do grupo observado, enquanto apenas $29 \%$ dos adultos que foram escolarizados, votaram nos últimos 5 anos.

Quando questionados de que forma a educação domiciliar afetou a vida adulta, $75.8 \%$ afirmou estar plenamente feliz por ter estudado em casa, $66 \%$ concordou plenamente que ter estudado em casa era uma vantagem, 58.9\% discordou plenamente de que a educação domiciliar limitava as oportunidades educacionais, $75.3 \%$ discordou plenamente de que a prática do homeschooling limitavas suas escolhas na carreira profissional, e $54 \%$ concordou plenamente em ter interesse em educar seus filhos no modelo de ensino desescolarizado.

Sobre ter prazer em viver, $98 \%$ dos homeschoolers responderam estar felizes ou muito felizes, apresentando um percentual de $2 \%$ que declarou não estar feliz. Diferente do quadro da população que foi escolarizada, onde 37\% respondeu estar feliz ou muito feliz enquanto $63 \%$ disse não ser feliz. $73 \%$ dos homeschoolers declararam viver uma vida emocionante, ao contrário dos que foram escolarizados, onde $52 \%$ revelou ter uma vida rotineira ou chata. $61.4 \%$ dos homeschoolers declararam-se muito satisfeitos com a profissão que desenvolviam, enquanto $39.7 \%$ dos adultos da população em geral responderam o mesmo nível de satisfação. $48.9 \%$ dos homeschoolers disse estar muito bem satisfeito com a situação financeira, contra $22.9 \%$ da população em geral que disse estar muito bem satisfeita. O nível de insatisfação financeira nos homeschoolers era de $7.8 \%$, enquanto dos adultos escolarizados estava em $28 \%$.

De acordo com informações divulgadas pelo NIERI (2019), alguns impactos imediatos podem ser observados durante a aplicação do ensino domiciliar. Abaixo alguns dados relevantes:

a) Impacto educacional: Os alunos homeschoolers apresentam desempenho acadêmico em um percentual de $15 \%$ a $30 \%$ superior aos dos alunos escolarizados. Esse número é elevado para um percentual do $23 \%$ a $42 \%$, quando os alunos 
referência, tanto homeschoolers quanto da educação escolarizada, são estudantes negros (RAY, 2015).

b) Impacto financeiro: Nos EUA, tendo em vista que as famílias adeptas ao ensino domiciliar não dependem de recursos públicos ou fiscais na educação básica dos filhos menores, o Governo deixa de gastar cerca de US $\$ 27$ bilhões. O gasto médio anual com cada aluno escolarizado é de US \$11.732, enquanto as famílias homeschoolers gastam cerca de US \$ 600 na educação de cada estudante (RAY, 2015).

Moreira $(2017$, p. 67,68$)$ entende que os impactos positivos advindos da prática da educação domiciliar, podem ser identificados em específicos fatores, sendo os mesmos, outrossim, motivações para a adoção da educação domiciliar. Fator acadêmico: o modelo de educação domiciliar consegue respeitar a individualidade da criança por meio de uma abordagem interdisciplinar, considerando as principais necessidades do educando, conforme previsão da DUDH. Diferente da escola, que, embora seja um mecanismo de apoio à educação, não é capaz de considerar as características específicas de cada criança, já que precisa oferecer um ensino massificado, que nem sempre tem conexão direta com a realidade ou o desenvolvimento de cada aluno.

Fator social: a criança homeschooler desenvolve um sistema de valores mais estável e fortalece a autoconfiança, ingredientes básicos para o que o autor chama de "socialização positiva". Moreira (2017, p. 68), afirma que a socialização das escolas é falha, porque não propicia intenso desenvolvimento cultural e linguístico necessário na fase da socialização primária, esse progresso ocorre de forma satisfatória no ambiente familiar, onde o menor aprende as referências de comportamento morais e sociais, além de conhecer o idioma nato. Ressalta ainda que a educação domiciliar possibilita $o$ contato com grande número de pessoas de diferentes faixas etárias, diminuindo chances de submissão às pressões de grupos. Exatamente o contrário do que ocorre na educação escolarizada, onde o contato é apenas com outras crianças e, geralmente da mesma faixa etária

Moreira (2017, p. 68), pontua também, o fator familiar: no homeschooling as crianças podem aprender os conteúdos sem deixar de conviver com os pais, de forma a valorizar o papel da família e garantir o sucesso do aprendizado, já que o êxito do 
conhecimento está alicerçado a uma estrutura familiar sólida e funcional em conjunto com um ensino de qualidade.

Embora os pontos positivos ressaltados, mister se faz expor ainda quanto aos pontos negativos da educação domiciliar. Frisa-se que, até o momento, não foi possível identificar pesquisas científicas capazes de embasar as razões que sustentam os argumentos sobre os impactos negativos do homeschooling. Contudo, pode-se identificar possíveis pontos negativos levantados frequentemente. De acordo com Lima (2014), psicopedagoga e mestre em neurolinguística pela Universidade Federal do Rio de Janeiro, a educação domiciliar é negativa porque ao oferecer um ensino desescolarizado, os pais impedem o menor de usufruir do convívio escolar, ferramenta primordial para o desenvolvimento infantil.

LIMA (2014), também pontua que a educação é um dever da escola e precisa ser desenvolvida através de uma programação pré-agendada e gradativa, o que o ensino domiciliar não é capaz de oferecer, por mais organizado e positivo que possa ser. Outrossim, para LIMA (2014), o vínculo emocional existente entre pais e filhos ocasiona intimidação ao menor e pode prejudicar o aprendizado, visto que acaba proporcionando um "jogo de forças" onde o educando está sempre em desvantagem.

Outro ponto levantado, é quanto as chances profissionais. Segundo Lima (2014), as crianças homeschoolers não aprendem por meio de lógicas interativas e dinâmicas e por isso não tem acesso as mesmas condições no mercado de trabalho dos alunos escolarizados. A autora pontua que dificilmente "esse indivíduo terá as mesmas condições em termos de desenvolvimento mental e de raciocínio e, também, emocional dos que aprenderam de modo interativo e dinâmico".

De acordo com Lima (2014), o fato de o homeschooling propor um ensino individualizado, não significa que a aprendizagem será eficaz. Para a autora, os métodos intensivos e acelerados não são garantia de que o educando poderá expressar suas convicções, experiências ou promover interações com outras pessoas. A autora destaca que, diante da falta de adaptação em uma escola, os pais devem procurar outra instituição de ensino ao invés de aderir ao ensino domiciliar.

O professor, pedagogo e diretor do Colégio Palmares em São Paulo, Edson D'addio, em entrevista concedida a Simone Saris do Jornal Folha de Londrina, pontuou 
que a falta de socialização é um dos maiores males que a educação domiciliar pode trazer. Segundo D'addio (Apud SARIS, 2018), a falta de convívio social no homeschooling, é um problema que pode causar impactos prejudiciais na vida adulta dos educandos, pois, segundo o professor, no modelo de ensino desescolarizado há carência de convívio diversificado, o que prejudica o processo de formação.

D'addio (Apud SARIS, 2018), também chama atenção para a falta de mecanismos de controle. A inexistência de legislação reguladora para acompanhar e oferecer orientação às famílias homeschoolers, pode ser uma porta aberta para o surgimento de famílias despreparadas adotando o modelo de ensino, sem possuir, por exemplo, condições metodológicas adequadas para um aprendizado eficaz.

Observou-se, que o homeschooling afeta positivamente na vida adulta das pessoas que receberam tal abordagem de ensino, porque, como exposto por meio de dados científicos, a educação domiciliar proporciona maior comprometimento civil e social, além de resultar em maior satisfação profissional, por exemplo. Quanto aos pontos negativos levantados, viu-se que questões como a falta de socialização na educação domiciliar é algo insustentável, já que a família é a principal responsável pela primeira fase do processo de socialização, transmitir valores culturais e comportamentais por meio de relações com pessoas de diferentes faixas etárias. E a socialização escolar é frágil porque não dispõe intenso relacionamento da criança com pessoas de diferentes idades ou culturas, oferecendo apenas o convívio com outras crianças da mesma idade e o fornecimento de conteúdos massificados sem considerar o potencial individual de cada educando.

\section{CONSIDERAÇÕES FINAIS}

Por meio deste trabalho foi possível estudar quanto a viabilidade jurídica do homeschooling no Brasil, mediante a ótica de tratados de direitos humanos. A pesquisa manteve como justificativa e pertinência temática, a necessidade de identificar o acompanhamento dado pelo ordenamento jurídico brasileiro à aplicação da educação domiciliar.

Alicerçado em uma metodologia indutiva, processo investigativo iniciou-se por meio de uma observação que forneceu base segura sobre a qual o conhecimento 
científico pôde ser construído, sendo obtido a partir da observação por indução. O método exigiu um exercício de concretização do Direito aplicável à realidade social, por meio de uma observação à luz do padrão constitucional e através de um procedimento argumentativo e racionalmente controlável.

Para deslinde do tema, foi necessária uma interpretação de caráter prático, em que a discussão do problema revelou-se com maior primazia sobre a discussão da norma em si. Foram levantados critérios e princípios para a resolução apropriada, sendo realizados procedimentos de coleta, classificação e análise de materiais bibliográficos, tabelas, estatísticas, análises de casos e matérias jornalísticas. Dessa forma, também foram utilizados métodos históricos, comparativos e empíricos no desenrolar do estudo.

Nesse sentido, a pergunta levantada foi, ante a relação entre os Tratados de Direitos Humanos em que o Brasil é signatário, e a educação, qual a abordagem da ordem jurídica brasileira quanto a aplicação do homeschooling no país? A investigação proporcionou o aclaramento quanto ao que dispõem tratados de direitos humanos sobre a educação, e até que ponto as diretrizes podem influenciar no sistema normativo jurídico do país e na realidade social das famílias brasileiras que optam pela educação domiciliar. Mister se fez, empreender a busca de subsídios para esclarecer sobre a estrutura didática e metodológica, bem como descortinar os impactos positivos e negativos da modalidade de ensino em evidência.

Observou-se que o processo educacional para o aprendizado por meio do homeschooling pode apresentar-se com diferentes abordagens, não possuindo uma estrutura didático-metodólogica específica, já que cada família é responsável por decidir qual metodologia utilizará no processo educacional, considerando o desenvolvimento da criança, o seu tipo de inteligência e as inúmeras individualidades de cada educando, bem como, de cada núcleo familiar, para que o menor possa, como proposto por Kumar (2008, p. 57), promover o desenvolvimento, a maturação e o florescimento do seu máximo potencial individual para a vida humana.

Quanto aos impactos positivos e negativos, observou-se, que o homeschooling afeta positivamente na vida adulta das pessoas que receberam tal abordagem de ensino, porque, como exposto por meio de dados científicos, a educação domiciliar 
proporciona maior comprometimento civil e social, além de resultar em maior satisfação profissional, por exemplo.

Sobre os pontos negativos mais levantados, viu-se que questões como a falta de socialização na educação domiciliar é algo insustentável, já que a família é a principal responsável pela primeira fase do processo de socialização, transmitindo valores culturais e comportamentais por meio de relações com pessoas de diferentes faixas etárias. Ficou demonstrado que a socialização escolar, em detrimento da socialização do homeschooling, é frágil porque não dispõe intenso relacionamento da criança com pessoas de diferentes faixas etárias ou de culturas diversas, oferecendo apenas o convívio com outras crianças da mesma idade e o fornecimento de conteúdos massificados sem considerar o potencial individual de cada educando.

Quanto ao ordenamento jurídico brasileiro e a contribuição de tratados de direitos humanos, verificou-se que os tratados estudados compõem o "bloco de constitucionalidade" e possuem status de norma supralegal, o que significa dizer que estão posicionados acima das normas infraconstitucionais e, embora abaixo do texto constitucional, integram o conteúdo material para o controle de convencionalidade.

Ademais, ao examinar o conceito de educação e investigar quanto a abordagem feita pelos tratados explorados, observou-se que tais documentos cooperam no sentido de amparar o ensino domiciliar no país, visto que não apresentam dispositivos para vedar o ensino desescolarizado. Pelo contrário, favorecem a defesa da prática, já que ampliam a interpretação quanto à possibilidade jurídica do homeschooling.

Vive-se hoje uma realidade onde o número de famílias homeschoolers cresce intensamente, e no cenário mundial, a educação domiciliar se mostra como um fenômeno presente nos cinco continentes e com reconhecimento em mais de sessenta países. Nesse diapasão, ignorar as diferenças sociológicas e temporais da realidade social brasileira desde a época de criação do ECA, da LDB e do Código Penal, até os dias atuais, é como negligenciar a existência de novos formatos pedagógicos, bem como fechar os olhos aos avanços educacionais dispostos.

Conclui-se com esta pesquisa, que a educação domiciliar é uma alternativa para as famílias brasileiras, em detrimento da educação formal escolarizada e diante da 
nova realidade social, cabe ao legislativo, promover a adequação normativa em um plano axiológico. A questão é, deveras, relevante e desafiadora. Dessa forma, deve o Estado reconhecer o homeschooling como uma possibilidade amparada pela legislação atinente ao "bloco de constitucionalidade" e possibilitar às famílias o direito ao exercício do poder familiar e ao respeito à individualidade de cada criança.

\section{REFERÊNCIAS}

ANDRADE, Édison Prado de. A educação familiar desescolarizada como um direito da criança e do adolescente: relevância, limites e possibilidades na ampliação do direito à educação. 2014. 403 f. Tese (Doutorado em Educação) - Faculdade de Educação, Universidade de São Paulo, São Paulo, 2014

ANED - Associação Nacional de Educação Domiciliar. Histórico. Disponível em: <https://www.aned.org.br/conheca/ed-no-brasil>. Acesso em: 10 ago 2019.

ARISTÓTELES. ÉTICA A NICÔMACO. Tradução de Leonel Vallandro e Gerd Bornheim da versão inglesa de W. D. Ross. 4. Ed. São Paulo: Nova Cultura. 1991.

BOARETO, Roberta. Do conceito de "Bloco de constitucionalidade" e sua configuração no direito Brasileiro como forma de interpretação constitucional. Jus Navigandi. 2014. Disponível em: <https://jus.com.br/artigos/34376/do-conceito-de-bloco-deconstitucionalidade-e-sua-configuracao-no-direito-brasileiro-como-forma-deinterpretacao-constitucional> Acesso em: 11 nov 2019.

BRASIL. Constituição (1988). Constituição da República Federativa do Brasil. Promulgada em 5 de outubro de 1988. Disponível em: $<$ http://www.planalto.gov.br/ccivil 03/constituicao/constituicaocompilado.htm>. Acesso em: 02 mar 2019.

. Decreto 678/1992. Pacto São José da Costa Rica. 1969. Disponível em: <http://www.planalto.gov.br/ccivll 03/decreto/D0678.htm>. Acesso em 28 fev 2019.

. Decreto no 99.710 de 21 de novembro de 1990. Promulga a Convenção Sobre os Direitos da Criança. Disponível em: $<$ http://www.planalto.gov.br/ccivil 03/decreto/1990-1994/D99710.htm>. Acesso em: 03 mar 2019.

Decreto-Lei no 2.848, de 7 de dezembro de 1940. Código Penal. Diário Oficial [da] República Federativa do Brasil, Brasília, DF, 16 jul. 1990. Disponível em: $<$ http://www.planalto.gov.br/ccivil 03/decreto-lei/del2848compilado.htm>. Acesso em: 
17 nov 2019.

. Lei no 8.069, de 13 de julho de 1990. Dispõe sobre o Estatuto da Criança e do Adolescente e dá outras providências. Diário Oficial [da] República Federativa do Brasil, Brasília, DF, 16 jul. 1990. Disponível em: <http://www.planalto.gov.br/ccivil 03/leis//8069.htm>. Acesso em: 17 nov 2019.

. Lei no 9.394, de 20 de dezembro de 1996. Estabelece as diretrizes e bases da educação nacional. Diário Oficial [da] República Federativa do Brasil, Brasília, DF, 16 jul. 1990. Disponível em: <http://www.planalto.gov.br/ccivil 03/leis/l9394.htm>. Acesso em: 17 nov 2019.

. IBGE - Instituto Brasileiro de Geografia e estatística. Pesquisa Nacional por Amostra de Domicílio. Taxa de trabalho infantil. 2009. Disponível em: $<$ https://seriesestatisticas.ibge.gov.br/series.aspx?vcodigo=PD329>. Acesso em: 14 nov 2019.

. Ministério da Educação. Encceja. Disponível em: <http://portal.mec.gov.br/encceja> Acesso em: 12 nov 2019.

. Ministério da Educação. Portaria no 2.270/2002. Disponível em: <http://download.inep.gov.br/educacao basica/encceja/legistacao/2002/portaria2270.pd f>. Acesso em: 12 nov 2019.

. Supremo Tribunal Federal. ADI 595-ES. Relator Ministro Celso de Melo. Disponível em: $<$ http://redir.stf.jus.br/paginadorpub/paginador.jsp?docTP=TP\&doclD=6631759 > . Acesso em: 17 nov 2019.

. Supremo Tribunal Federal. Informativos no 258 de 25 de fevereiro a 1ำ de março de 2002. Disponível em:

$<$ http://www.stf.jus.br/arquivo/informativo/documento/informativo258.htm>. Acesso em: 17 nov 2019.

DURKHEIM. E. Educação e sociologia. São Paulo: Melhoramentos, 1978.

GONÇALVES, Carlos Roberto. Direito Civil Brasileiro, Volume III: contratos e atos unilaterais. 6 ${ }^{\text {a }}$ Ed., São Paulo: Saraiva, 2009.

KUMAR, Satish; AHMAD, Sajjad. MEANING, AIMS AND PROCESS OF EDUCATION. School of Open Learning, University of Delhi,5, Cavalry Lane. 2008. Disponível em: $<$ https://www.academia.edu/7686933/LESSON -

1 MEANING AIMS AND PROCESS OF EDUCATION -Satish Kumar>. Acesso em: 15 nov 2019. 
LIMA, Eloísa. Vantagens e desvantagens do 'homeschooling', o ensino domiciliar. Último Segundo. 2014. Disponível em:

$<$ https://ultimosegundo.ig.com.br/educacao/2014-09-01/vantagens-e-desvantagens-dohomeschooling-o-ensino-domiciliar.html>. Acesso em: 17 nov 2019.

MAZZUOLI, Valério de Oliveira. Curso de Direitos Humanos. $5^{a}$ ed., São Paulo: Método. 2018.

MOREIRA, Alexandre Magno Fernandes. O Direito à Educação Domiciliar. 1ª ed., Brasília: Editora Monergismo, 2017.

NUCCI, Guilherme de Souza. CÓDIGO PENAL COMENTADO. 14. ed. rev. e atual. Rio de Janeiro: Forense, 2014.

ONU. Declaração Universal dos Direitos Humanos. 1948. Disponível em:

<https://nacoesunidas.org/direitoshumanos/declaracao/>. Acesso em: 20 fev 2019.

PEREIRA, Rodolfo Viana. Hermenêutica Filosófica e Constitucional. 2.ed. Belo Horizonte: Del Rey, 2007.

RAY, Brian D. Research, studies and scholarships at home. National Home Education Research Institute. 2015. Disponível em:

$<$ https://www.nheri.org/homeschooling-research-studies-and-scholarship/>. Acesso em: 16 nov 2019.

RAY, Brian D.. Homeschooling GROWS UP. National Home Education Research Institute. Salem, Oregon: 2003. Disponível em:

$<$ https://hslda.org/content/research/ray2003/homeschoolinggrowsup.pdf $>$. Acesso em 16 nov 2019.

. African American Homeschool Parents' Motivations for Homeschooling and Their Black Children's Academic Achievement. Journal of School Choice, 9 : 71-96 2015. Disponível em: <https://www.nheri.org/african-american-homeschoolparents-motivations-for-homeschooling-and-their-black-childrens-academicachievement/>. Acesso em: 16 nov 2019. SARIS, Simoni. Brasil não está preparado para educação domiciliar, avalia pedagogo. $\mathrm{FL}$

FOLHA DE LONDRINA. 2018. Disponível em:

$<$ https://www.folhadelondrina.com.br/opiniao/brasil-nao-esta-preparado-para-educacaodomiciliar-avalia-pedagogo-1016638.html>. Acesso em: 17 nov 2019.

SCHELB, Guilherme Zanina. Conflitos e Violência na Escola - Guia legal e prático para professores e famílias. Brasília: Inove Gráfica e Editora, 2015.

VARELLA, Marcelo Dias. Direito internacional público. São Paulo: Saraiva, 2011. 